\title{
Application of Small Area Estimation of SME in Albania for Survey Research Method of Analyse
}

PhD Miftr Ramosacaj

PhD candidate, Math Department, University of Vlora, Albania, Email:mramosacaj@yahoo.com

\section{Prof. Ass. Dr. Alba Robert Dumi}

Director of Graduate School, "Ismail Qemali"Vlore University, Albania, University of Tirana, Albania,Management Department,

Doi:10.5901/mjss.2014.v5n13p409

Email: alba.besi12@gmail.com

\begin{abstract}
Challenges in identifying the appropriate electoral system and institutional arrangements to achieve inclusiveness require developing an adequate knowledge of the local electorate and identifying a combination of electoral system and affirmative action which best suits the structural as well as institutional context. The capacity of public administration was weak; the system, stemming from a party focused environment, was highly politicized. Corruption was pervasive in every facet of the public sector. Citizens feared public administration and did not trust it to provide even the most basic services in a fair or impartial way. It highlighted the problems of Albania's economic governance capacity and, from an administrative standpoint, reaffirmed and highlighted the inefficacy of a public administration, unable to enforce its laws and regulations. As the public's confidence in Albanian institutions had been significantly eroded by the recent events, restoring the public's trust in the government became the main priority of the government. In this paper research we are trying to analyze empirically: 1) the impact of Application of Small Area Estimation of SME in Albania, 2) reforming in Albanian public administration, like Balkan countries. Based on positive political theory and the benefit principle of taxation, we are present new math models of ASEA survey and the concrete results of ASEA.
\end{abstract}

Keywords: ASAE survey, Administrative system, Implementing financial reforms, Accountable \& Administration strength, Math method of survey.

\section{Introduction}

This study empirically examines the impact of debt management policies on borrowing costs incurred by state governments when issuing debt in the municipal bond market. Based on positive political theory and the benefit principle of taxation, it is proposed that states that adhere to best practice debt management policies transmit signals to the credit ratings, investment community and taxpayers that the government should meet its obligations in a timely manner, resulting in lower debt costs. This was my entire point with temporarily nationalizing the banks

The EU remains Albania's main trading partner, providing $64.1 \%$ of Albania's imports and receiving $70.2 \%$ of exports as of September 2010. Trade with Italy and Greece, although steadily declining since 2008, continues to represent the largest share of EU trade, with a combined $40.8 \%$ of imports and $56.4 \%$ of exports as of September 2010. Other major trading partners include Turkey, China, and Germany. (Anthony, R. N. and Dearden 1980)

The impact of CEFTA in Albania's trade with member countries has been small. Albanian case study during this on the outcome of electoral systems and local politics and how more inclusive systems of local governance can be developed. It was emphasis that the choice of electoral system can create opportunities for greater representation of women, ethnic minorities, the poor and other disadvantaged groups in local government. Structural as well as institutional factors pose major challenges faced in achieving this outcome. Affirmative action was not seen as a viable long-term solution for achieving increased representation of these groups.

\subsection{Albanian transition and needs for changes in public sectors.}

Albania Government worked with donors on the public financial management agenda by strengthening core public financial management units (Ministry of Finance, Supreme Audit Institute, Procurement Directorate within the Office of the 
Prime Minister) as well as the financial management units within each line agency (e.g., budget departments within line Ministries). On matters relating to public sector human resource management, the reform strategy envisaged addressing this issue in two major stages: civil service reform and broader public sector human resource management reform. During the stage, the reforms aimed to create the managerial and professional nucleus required to lead any serious efforts to improve the accountability and performance of public institutions. There was some progress as regards the establishment of technical infrastructure for electronic signature.

In January, the National Agency for the Information Society was accredited by the National Authority for Electronic Certification to provide the public administration with certificates enabling it to process electronic documents as from September. The first application, to be used by the General Directorate of Customs, is being set up. Licensing of a second private e-certification service provider is ongoing. The number of businesses that have been given e-certification increased to about 500 . The implementation of e-signature by the state authorities has yet to be verified. In the area of corporate accounting, preparations for aligning legislation on accounting and national accounting standards with the acquis have started. The National Accounting Council increased efforts to strengthen its capacity by training its staff and working on a series of internal guidelines. The membership of the Council's board was revised in May. In the field of auditing, the Public Oversight Body continued its monitoring activities and was involved in a direct review of the quality of auditing of public interest entities.

\subsection{What is Small Area?}

Small Area is a small geographic area within a larger geographic area or a small demographic group within a larger demographic group. The sample size in the domain of interest is too small to use a standard estimator. Most small area estimation methods borrow strength from related or similar areas using auxiliary data. There is growing demand from the public for reliable small area statistics. At the design stage, we don't consider attaining precision at the state and function code level. However, we have to handle this challenge at the estimation stage.

Let $g$ represent state and $f$ represent function code level. We want to estimate the total of employees or payroll information at the state by function level:

$$
{ }^{Y} g f=\sum_{i \in U_{g f}}^{Y} g f i
$$

where $U$ is the universe of function codes in all states, and $U_{g f}$ is the universe of function code $f$, state $g$. Thus, $U_{g f}$ is subset of $U$, that is, $U_{g f} \subset U$. The sample size for function code $f, n_{f}$, is less than or equal to the sample size $\mathrm{n}$, that is, $n_{f} \leq n$. The domain of sample for function code level $f$ of state $g$ is the intersection of the sample domain of state $g$ and the universe of function code $f$ and state $g, S_{g f}=S_{g} \cap U_{g f}$.

In some cases, the changes in Employment statistics are relatively stable. Therefore, a linear regression is suitable for some state by government type cells as done prior to Fiscal Year (FY) 2009. However, due to small sample sizes and poor fits on many cells, a small area estimation method (SAE) is more appropriate. SAE is only applied on PPS sample. For certainties, the direct estimate was used. Information on Births and Non-Activity (B\&N) units is not available at the sampling stage. Therefore, we sample B\&N separately from the PPS and Certainties sample.

Figure 1 briefly shows how we estimated the variable of interest in each cell of state by function code table. We applied the design-based direct estimator (Horvitz-Thompson), and the synthetic estimator in each cell. The direct estimator has high variability due to the small sizes. On the other hand the synthetic estimator reduces the variability but introduces some bias. Therefore, we introduce the composite estimator, which is a weighted average of those two estimators. We also modified the direct estimator (modified direct) from borrowing strength from similar cells to smooth the direct estimator. We will go through each of our estimators in detail in subsequent sections. Source: SAE Wahinton research 2007 


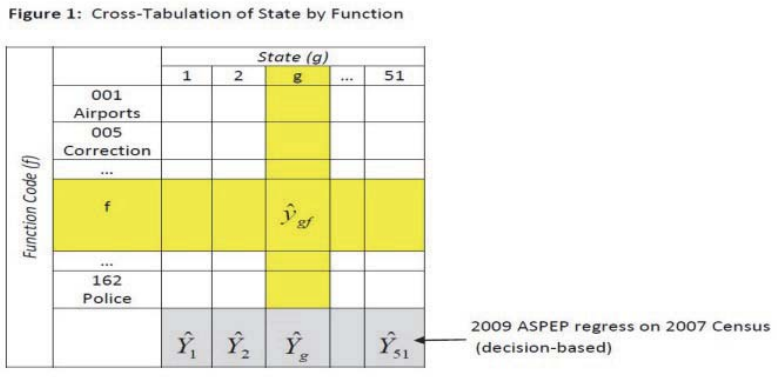

Figure 1SEA Washinton research, briefly shows how we estimated the variable of interest in each cell of state by function code table. We applied the design-based direct estimator (Horvitz-Thompson), and the synthetic estimator in each cell. The direct estimator has high variability due to the small sizes

The roadmap for the reform of accounting and auditing for the period 2013-2015 was approved in August. The independence of the Public Oversight Body and its funding remain to be addressed as part of the reform. Some progress was made in the field of company law through the adoption of legislation in the area of cross-border mergers. Some progress was made in the areas of corporate 23accounting and auditing, but legislation remains to be aligned with the acquis. The Public Oversight Body needs to be strengthened. Overall, preparations are moderately advanced method, wich we are make like methodology in this paper research.

\section{Literature Review and Hypotheses}

A general design-based direct estimator for the total is:

$$
\hat{t}_{y, g f}=\sum_{i \in S} w_{i, g f} y_{i, g f} .
$$

where the weight, $w_{i}=\frac{1}{\pi_{i}}$, and $\pi_{i}$ is the inclusion probability for unit $i$ in state $g$ and function code $f$. In this paper, we also denote $\hat{t}_{y, g f}$ as $\hat{Y}_{g f}^{H T}$.

\subsection{Decision-based estimator}

The Decision-based (DB) method helps to estimate the synthetic in each cell by providing a stable state total as a reliable estimator in a large area covering all small areas, states by function code level. DB was a process of testing the possibility of combining the strata. This strengthened statistical models for the area of estimation. Source: SAE Wahinton research 2007

The state total was estimated by a single stratum weighted regression (GREG) estimator specified as follows:

$$
\begin{gathered}
\hat{t}_{y, G R E G}=\hat{t}_{y, \pi}+\hat{b}\left(t_{x}-\hat{t}_{x, \pi}\right) \\
\text { where } t_{x}=\sum_{i \in U} x_{i}, \quad \hat{t}_{x, \pi}=\sum_{i \in S} \frac{x_{i}}{\pi_{i}}, \hat{t}_{y, \pi}=\sum_{i \in S} \frac{y_{i}}{\pi_{i}}, \hat{b}=\frac{\sum_{i \in S}\left(x_{i}-\bar{x}\right)\left(y_{i}-\bar{y}\right) / \pi_{i}}{\sum_{i \in S}\left(x_{i}-\bar{x}\right)^{2} / \pi_{i}}, \pi_{i} \text { is }
\end{gathered}
$$

The inclusion probability, and $x_{i}$ is the auxiliary data from the Employment portion of the Census of Governments for government unit $i$.

\subsubsection{Direct estimator (Horvitz-Thompson)}

Countries wishing to join the EU can proceed from one stage of the process to the next, but only once all the conditions at 
each stage have been met. In this way, the prospect of accession acts as a powerful incentive to reform. The EU policy on enlargement ensures that the process is meticulously managed, so that accession brings benefits simultaneously to the EU and to the countries that join it. At that time, Albania's administrative system was considered chaotic and ineffective. Its administrative culture - a combination of many influences - emphasized security over service delivery. (Blake,R.R \& Mounton, J.S.) The capacity of public administration was weak; the system, stemming from a party focused environment, was highly politicized. Corruption was pervasive in every facet of the public sector. Citizens feared public administration and did not trust it to provide even the most basic services in a fair or impartial way.

\subsection{Public Administration and EU policy of enlargement in Albania}

The responsibility for the relatively high standards of living involved here certainly does not rest completely with unionism.clearly, one must also examine such a variety of other factors as skill levels, industrial ability to pay, imperfections in the product market, and industrial productivity (among others) in explaining these wage levels. And one can readily cite such unionized areas as the boot and shoe industry and the meatpacking industry, where the overall situation often allows no real wage improvement at all and, consequently, none isreceived by organized labor.

$H$ 1.The definite upsurge in unionism among government employees-although probably attributable far more to enabling legislation than to ony pronounced rank-and-file militancy-is combining with the (lesser) emergence of collective bargaining in other white collar areas to gradually weaken the nonmember "s traditional association of organized labor with manual work

But the hazards of accepting the more impressive union bargaining totals at their face value are not particularly relevant in this context. Misleadingly or not, such dollar amounts often symbolize in a highly visible fashion the ability of unionism to effect dramatic wage gains. And, as the gap between the incomes of the blue collar and white collar worlds continues to widen, a greater willingness to consider union membership may conceivably be the result. Indeed, appreciation of the fact that snobbishness for some of the increased willingness of at least teachers and to undertake such a consideration.

\subsection{Variance Estimation}

Due to the complexity of the two-stage sampling design with the cut-off technique, we calculated the approximate variance (AV) of the composite estimator. AV is estimated on the non sub-sampling sample. Besides, there are B\&N units, which are very small and contribute a small amount in the survey total. We assume the variance on B\&N is ignorable. Source: SAE Wahinton research 2007

$$
\begin{aligned}
& \text { The coefficient of variance, CV, is estimated by } \frac{\sqrt{\operatorname{Var}(\hat{y})}}{\hat{y}} \text {, where } \hat{y} \text { is the composite } \\
& \text { estimated on PPS, certainties, and B\&N. }
\end{aligned}
$$

The government units were sampled by state and government type. However, the variance is required for the cell of state and function code, which we don't know the size in advance. Therefore, in order to estimate the variance for the cell state by function code, we treated each combination $D=$ (state, function code) as a domain in the sample, which is identified by the indicator $I_{D}=1$ if the unit belongs to $D$, and 0 otherwise. We used Taylor series method for the variance estimation in which the variation among different units of the same function code was taken into account. The domain total is:

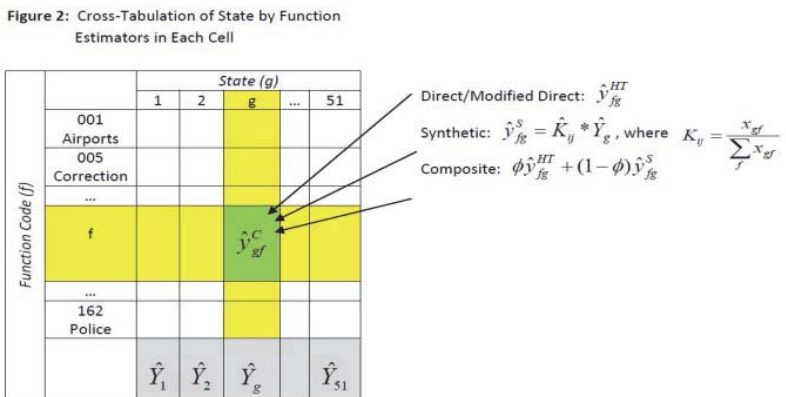




$$
\hat{Y}_{D}=\Sigma_{g} \sum_{f} \sum_{j} I_{D} w_{h f j} y_{f g j} \text {, where } g=\text { state, } f=\text { function code, and } j=\text { unit } j^{\text {th. }} \text {. }
$$

The estimated variance is:

$$
\begin{aligned}
& \hat{V}\left(\hat{Y}_{D}\right)=\sum_{g} \hat{V}_{g}\left(\hat{Y}_{D}\right), \text { where } \\
& \text { If } n_{g}>1, \\
& \hat{V}_{g}\left(\hat{Y}_{D}\right)=\frac{n_{g}\left(1-f_{g}\right)}{n_{g}-1} \sum_{i=1}^{n_{g}}\left(z_{g i .}-\bar{z}_{g . .}\right)^{2}
\end{aligned}
$$

$\mathrm{H}$ 2.It is probably also only a question of time before considerably more aggressive, imaginative, and empathetic leadership than organized labor now possesses comes to the fore, which would also make widespread white collar unionization more likely.

\subsubsection{The impact, performance and cultural development in Albania and Balkan.}

After the fall of socialism, Albania largely succeeded in providing targeted assistance to the poor when compared with other low-income countries (Alderman 2002). And, despite strong turmoil, Albania has found its way to becoming a democratic nation-state with a commitment to gender equality. These can be seen in the approval of a democratic constitution in 1998 and the ratification of international agreements, like the Convention on the Elimination of all Forms of Discrimination in Albanian public administration. (Calloni 2002) Weak lending, affecting both households and investors, reflects tighter credit standards applied by banks amid a high and rising share of non-performing loans and subdued credit demand due to economic uncertainties. In an effort to reinvigorate lending, the BoA adopted specific regulatory changes in March aiming at releasing financial resources for banks and channelling them towards lending to the private sector, but so far credit growth has not picked up.

In general, the Albanian banking system remained well capitalised and liquid. The net results of the banking system in 2012 amounted to $€ 26.71$ million, reflecting a significant increase compared with the previous year. The capital adequacy ratio increased to $16.7 \%$ in May from $15.6 \%$ at the end of 2011, with each individual bank remaining above the $12 \%$ regulatory minimum. The ratio of liquidity assets to short-term liabilities as of the end of December 2012 increased to $36.7 \%$, comfortably exceeding the minimum regulatory requirement of $25 \%$.

Deposits were the main source of financing and parent-bank credit lines were significantly lower than at the end of 2011, strengthening the banking system's resilience to foreign shocks. However, banks' exposure to credit risk has increased, as the ratio of non-performing loans rose further to $24.4 \%$ in the second quarter of 2013 compared to $21.2 \%$ a year earlier.

This has led to a surge in loan loss provisioning, up by $24.3 \%$ in June on an annual basis.

Total assets of the non-banking financial sector stood at $2.8 \%$ of GDP. The insurance market, in which foreign capital has a 50\% stake, increased its gross written premium revenues by some $9 \%$ in 2012 but its share of GDP remains low. The securities market focused on government bonds and saw two new investment funds start up. The voluntary pension market grew by $83 \%$ in 2012 from a very low base and is still in the very early stages of development.

One of the main gender concerns in Albania today seems to be the missing link between putative and real equality in terms of access to employment, businesses, credit institutions, health care and social services. There are also questions about gender equality in civic participation and political decision-making. Albanian law prohibits gender discrimination and job segregation in public and private employment.

$H$ 3.The Albanian - reforms aimed to create the managerial and professional nucleus required to lead any serious efforts to improve the accountability and performance of public institutions.

Balkan countries and Albanian government, on the other hand, should meet its obligations in a timely manner, resulting in lower debt costs. Although the field of entrepreneurship in Balkan is recognized as being of fundamental importance for Balkan economy, and many researchers throughout the world have turned their attention to it, there's, as yet, no agreement as to the research object in this scientific field.

The composite estimator was used to estimate the survey totals in each cell (state by function) of the ASPEP. As mentioned earlier, the composite estimator is the weighted average of the two estimators: the design-based and the synthetic. The composite balances out the instability of the unbiased due to small sample sizes with the synthetic quantity. The weight pulls the estimate to the design unbiased estimate when it has enough data, and towards the 
synthetic estimate when there is insufficient sample size in the small area (Rao, 2003). Source: SAE Wahinton research 2007

By applying the methods described, we created Table 3 which is a typical illustration of our data analysis. Those methods included a combination of Decision-based estimation and an application of a SAE method. Table 3 is for the variable, Full Time Equivalent Employment, in several randomly selected states. The 2007 data (census data) is included in the Table 3 to see the changes of the variable overtime from different estimators. It is not used to evaluate different estimators. However, for some stable variable like Full Time Employees, 2007 census data is useful to see the performance of the estimators. The conclusions are as follows:

- When there were no observed sampled units, we used the synthetic estimate where the design-based direct estimates were not present. For example, there were no samples units in higher education,we obtained a reasonable synthetic estimate.

- The synthetic estimates were stable in small size areas where the design-unbiased estimates were very volatile.

- The modified direct estimates were closer to the 2007 census values.

- When the sample sizes were big enough, all the estimators performed well and they were close to each other.

- The composite using the modified direct estimator was close to the 2007 Census values most often.
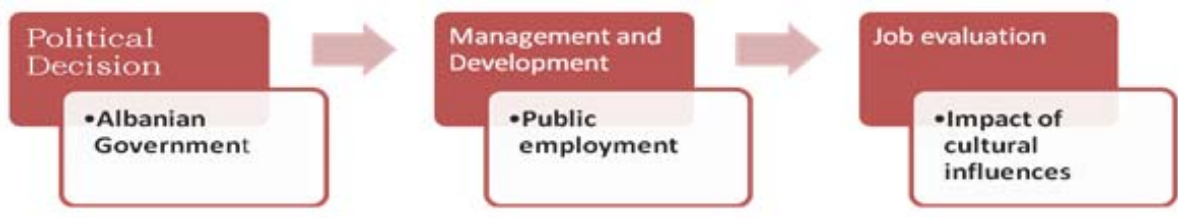

Table 2: The heads of central and local government institutions, Source: Albanian BB for Albania, report 2011

\subsection{The economic dimension of regional cooperation}

Regional cooperation is essential for increasing prosperity and economic growth. Economic development is a key issue if the WBs countries are to make better, faster progress towards European integration. In many areas, such as trade, energy and transport, because of the limited size of each WBs country and the fragmentation of the economic space in the region, there is no other option but to embark on intense regional cooperation as the only realistic way forward. Enhanced regional cooperation in the economic field is just plain common sense. Beyond the intra-regional challenges, the ultimate goal is to reconnect the WBs countries fully with all their neighbours, EU Member States and candidate countries alike.

\section{Research Goal and Data Collected}

The Development Credit Agreement (DCA) states the objective of the project to be: The objective of the Project is to assist the Borrower to improve its capacity with regard to policy formulation and coordination, and administrative performance so as to create conditions that will encourage the Department of Public Administration of the Borrower to improve their service delivery. This paper presents two applications: Decision-based and Small Area Estimation methods. They were applied to the estimation of Annual Survey of Public Employment and Payroll. SAE provides the composite estimate which smoothes the design unbiased estimators in small areas by introducing the synthetic term. The synthetic estimate is more reliable when derived from the Decision-based estimates. This property cannot be obtained from a simple regression synthetic.

With these two methods arecombined, we obtained better estimates than those of using direct estimators or with linear regression where the linear relationship is weak or even does not exist. 


\subsection{Albania's administrative system and public sector.}

At that time, Albania's administrative system was considered chaotic and ineffective. Its administrative culture - a combination of many influences - emphasized security over service delivery. The capacity of public administration was weak; the system, stemming from a party focused environment, was highly politicized. Corruption was pervasive in every facet of the public sector. Citizens feared public administration and did not trust it to provide even the most basic services in a fair or impartial way.

Source: (Dumi A, MJSCER Roma Italy, vol 2, nr 4, 2013)

\section{Methodology}

\subsection{Research Goal}

In this survey we aim to identify the Application of Small Area Estimation of SME in Albania.During the first years of the reform, the government focused on improving the legislative framework to ensure that its objectives could be achieved. By 1999, and prior to the approval of the credit under review by this ICR, the Government had identified and adopted a large number of measures which provided important institutional capacity to strengthen the public administration. As regards horizontal issues, the government allocated about $€ 6.8$ million in 2013 for direct support and national investment schemes in agriculture and agro-processing. Agricultural production in 2012 increased slightly, mostly due to improved production in fruit trees and olives.

Here, Y represents the survey total of key variables: full-time employment, full-time payroll, part-time employment, part-time payroll, part-time hours, full-time equivalent employment, total payroll, and total employment. We describe all the estimators used in our estimation process: Direct (Horvitz-Thompson), Decision-based, Synthetic, Composite, Modified Direct, and the Composite estimator.Source: SAE Wahinton research 2007

Part of the growth is linked to the government direct support schemes that have encouraged the planting of new trees. While exports increased, the trade balance has improved marginally. There has been good progress with agricultural statistics. Since the beginning of 2013 the National Statistics Institute (INSTAT) has been responsible for agricultural statistics. The Census of Agricultural Holdings was conducted in October 2012.

Bias of the synthetic estimator is the biggest disadvantage for synthetic estimation. Departures from the assumption may lead to large biases. Empirical studies have mixed results on the accuracy of synthetic estimators. The bias may not be estimated from the data.The variance estimator for the complicated composite estimator derived from a Decision-based method needs separate research which will be presented in a future paper.

\section{Research Data and Indicators of Performance}

We have some outstanding issues which need further research. We need to develop a simple and good variance estimator formula for the composite estimator other than a resampling method. Regarding the weight, $\hat{\varphi_{g}}$, in the composite estimation method, we replace $\hat{\varphi_{g}}=0.5$ when it was negative. Lahiri and Pramanik (2010) extended a method from Gonzalez \& Waksberg (1973), which used Average Design-based Mean Squared Error (AMSE) to stabilized the $\hat{\varphi_{g}}$ . We will apply this method in our production in the future. We will also explore in more detail the application of the Empirical Bayes method with an alternative assumption other than normality. Finally, we will apply this method for other surveys in the Governments, like the Annual Finance Survey (AFS).

\section{Conclusions}

Bias of the synthetic estimator is the biggest disadvantage for synthetic estimation. Departures from the assumption may lead to large biases. Empirical studies have mixed results on the accuracy of synthetic estimators. The bias may not be estimated from the data.

The variance estimator for the complicated composite estimator derived from a Decision-based method needs separate research which will be presented in a future paper. Carmines, E.G \& Maciver, J.P. analyzing models with unobserved variables: Analysis of covariance structures. This paper presents two applications: Decision-based and Small Area Estimation methods. They were applied to the estimation of Annual Survey of Public Employment and Payroll. SAE provides the composite estimate which smoothes the design unbiased estimators in small areas by introducing the 
synthetic term. The synthetic estimate is more reliable when derived from the Decision-based estimates. This property cannot be obtained from a simple regression synthetic.

With these two methods arecombined, we obtained better estimates than those of using direct estimators or with linear regression where the linear relationship is weak or even does not exist.

\section{Future Research}

We have some outstanding issues which need further research. We need to develop a simple and good variance estimator formula for the composite estimator other than a resampling method. Regarding the weight, $\hat{\varphi_{g}}$, in the composite estimation method, we replace $\hat{\varphi_{g}}=0.5$ when it was negative. Lahiri and Pramanik (2010) extended a method from Gonzalez \& Waksberg (1973), which used Average Design-based Mean Squared Error (AMSE) to stabilized the $\hat{\varphi_{g}}$ . We will apply this method in our production in the future. We will also explore in more detail the application of the Empirical Bayes method with an alternative assumption other than normality. Carmines, E.G \& Maciver, J.P. analyzing models with unobserved variables: Analysis of covariance structures.

Finally, we will apply this method for other surveys in the Governments, like the Annual Finance Survey (AFS). According to preliminary results, the total number of agricultural holdings is 324013 , compared to 350654 in 2010. The share of holdings keeping livestock fell from $84 \%$ in 2010 to $71 \%$ in 2012. The work on setting up a functional land cadastre continues to progress very slowly. Under the Law on agricultural cooperation companies, new cooperatives have been registered for the production of oil, cereals and vegetables. The work on creating a functioning electronic agricultural information system (farm register, animal register, etc.) must intensify in order to create a basis for sound financial management of national and EU assistance. (Albania 2013 Enlargement Strategy and Main Challenges 20132014)

Supported by the Structural Adjustment Credit (SAC), and Public Expenditure Support Credit, the government undertook a number of pivotal actions which defined the framework of reform. Among them, Parliament revised the Civil Service Law in November 1999, and an independent Civil Service Commission (CSC) was created and staffed. (Bishop, E. B.1986)

Credit lines are considered as a limit granted to a customer for use within a specific period of time. Micro businesses often use working capital to pay short term obligations as inventory or it can be also utilize for long term projects such as renovations or expansion. If working capital dips too low, a business risks running out of cash. ( Albania 2013 Progress Report Enlargement Strategy and Main Challenges 2013-2014).

\section{References}

Administrative Science Quarterly, 1966, 11, 138-263.

Ashby, W.R Desing for a brain. New York: wiley, 1952.

Bass, B.M. stogdill's handbook of leadership: a survery of theory in research. New York: free press, 1981.

Bass, B.M. bass and stogdill's handbook of leadership. Theory, research and managerial application ( $3^{\text {rd }}$ ed) New York Free Press, 1990.

Blake, R.R \& Mounton, J.S.The managerial grid Houston, TX: Gulf, 1964.

Bowers, D.G \& Seashore, S.E. "Predicting organizational effectiveness with a four-factor theory of leadership"

Carmines, E.G \& Maciver, J.P. analyzing models with unobserved variables: Analysis of covariance structures.

Dansereau, F...Graen, G \& Haga, W.J. A vertical dyad linkage approach to leadership within formal organizations: a longitudinal investigation of the function-making process. "Organizational Behavior and Human Performance" 1975, 13(1), 46-78.

Dobbins, G.H \& Platz, S.J. sex differences in leadership: How real are they? Academy of Management Review, 1986, 11(1), 118-127.

Dumi, A. MJESS Roma Italy." EU and Albania reforming stade" vol 3, nr 5, 2013, pp 146

Dumi, A. JERM Roma Italy." Math analyze and SME development" vol 1,nr 1, 2014, pp 8

Fidler, F.E. a theory of leadership effectiveness. New York: McGraw-Hill, 1967.

Gillespie, H.R. An investigation of current management/leadership styles of manufacturing executives in Harris, T.G. the post-capitalist executive: an interview with Peter F.Drucker. Harvard business review, 1993, 71, 114-122.

Hart, S.L \& Quinn, R.E. Roles executives play: CEOs, behavioral complexity, and firm performance. Human Relations, 1993, 46(5), 543574.

SEA Washinton research, 2007, pp 1245, 1357, 1389

Hersey, P \& Blanchart, K.H. Management of organizational behavior: utilizing human resource (4th , ed) Englewood Cliffs, NJ: PrenticeHall, 1982. 